Article

\title{
Integrated Participatory and Collaborative Risk Mapping for Enhancing Disaster Resilience
}

\author{
Wei Liu ${ }^{1, *}$, Sumit Dugar ${ }^{2}$, Ian McCallum ${ }^{1}$, Gaurav Thapa ${ }^{3}$, Linda See ${ }^{1}$ (D), Prakash Khadka ${ }^{4}$, \\ Nama Budhathoki ${ }^{3}$, Sarah Brown ${ }^{5}$, Reinhard Mechler ${ }^{1}$, Steffen Fritz ${ }^{1}$ and Puja Shakya ${ }^{2}$ \\ 1 International Institute for Applied Systems Analysis (IIASA), Schlossplatz 1, 2361 Laxenburg, Austria; \\ mccallum@iiasa.ac.at (I.M.); see@iiasa.ac.at (L.S.); mechler@iiasa.ac.at (R.M.); fritz@iiasa.ac.at (S.F.); \\ 2 Practical Action Consulting (PAC) Nepal, Narayan Gopal Sadak, PaniPokhari, Maharajgunj, \\ Kathmandu 44600, Nepal; sumitdugar@hotmail.com (S.D.); Puja.Shakya@practicalaction.org.np (P.S.) \\ 3 Kathmandu Living Labs (KLL), 1474 Lamtangin Marg, Chundevi, Kathmandu 44616, Nepal; \\ gaurav.thapa@kathmandulivinglabs.org (G.T.); namabudhathoki@gmail.com (N.B.); \\ 4 Center for Social Development and Research (CSDR), Rajapur, Bardiya 21800, Nepal; \\ khadkaprakash3@gmail.com \\ 5 Practical Action Consulting (PAC), The Schumacher Centre, Bourton on Dunsmore, Rugby, \\ Warwickshire CV23 9QZ, UK; Sarah.Brown@practicalaction.org.uk \\ * Correspondence: liuw@iiasa.ac.at; Tel.: +43-2236-807-255
}

Received: 29 November 2017; Accepted: 17 February 2018; Published: 21 February 2018

\begin{abstract}
Critical knowledge gaps seriously hinder efforts for building disaster resilience at all levels, especially in disaster-prone least developed countries. Information deficiency is most serious at local levels, especially in terms of spatial information on risk, resources, and capacities of communities. To tackle this challenge, we develop a general methodological approach that integrates community-based participatory mapping processes, one that has been widely used by governments and non-government organizations in the fields of natural resources management, disaster risk reduction and rural development, with emerging collaborative digital mapping techniques. We demonstrate the value and potential of this integrated participatory and collaborative mapping approach by conducting a pilot study in the flood-prone lower Karnali river basin in Western Nepal. The process engaged a wide range of stakeholders and non-stakeholder citizens to co-produce locally relevant geographic information on resources, capacities, and flood risks of selected communities. The new digital community maps are richer in content, more accurate, and easier to update and share than those produced by conventional Vulnerability and Capacity Assessments (VCAs), a variant of Participatory Rural Appraisal (PRA), that is widely used by various government and non-government organizations. We discuss how this integrated mapping approach may provide an effective link between coordinating and implementing local disaster risk reduction and resilience building interventions to designing and informing regional development plans, as well as its limitations in terms of technological barrier, map ownership, and empowerment potential.
\end{abstract}

Keywords: collaborative mapping; co-production; disaster resilience; flood risk; Nepal; OpenStreetMap; participatory mapping; vulnerability and capacity assessment (VCA)

\section{Introduction}

\subsection{Background: Spatial Risk Information Deficiency Hinders Disaster Resilience Building}

The impacts of natural disasters have been substantial and increasing, both in terms of direct loss of lives and assets, and indirect erosion of livelihood and development opportunities. Population growth, urbanization, and climate change are expected to exacerbate the situation [1-3]. Globally, floods are 
among the most devastating disasters, with about 1.5 billion people having been affected since 2000 [4]. Of the top 20 countries whose inhabitants are most affected by floods, 19 are developing countries and emerging economies, of which 11 are in South and Southeast Asia [5].

There is a strong need to transform the way disaster risk is managed on the ground so that disaster-prone communities can prosper despite the occurrence of hazards from time to time. This calls for a more integrated and pro-active perspective into the management of disaster risks to broader environmental and development planning across scales [6-10], and building disaster resilience of communities, so that they can "bounce forward" and resume social, ecological, and economic development after disaster events [7,11]. Building community disaster resilience requires evidence-based understanding of disaster risk on the ground, including all dimensions across vulnerability, exposure, and hazard [8], as well as communities' capacities (such as in the form of human, social, physical, financial, and natural capitals) [12].

In flood-prone regions, the principal source of information is flood hazard maps derived from river-basin-scale hydrological models and coarse-resolution projections of future floods [13-15]. At global and regional scales, satellite-based remote sensing has provided substantial observational databases of flood events [16-18] and flood early warning systems are being developed [19], providing useful entry points for national and regional flood risk management. However, a major gap still exists between what the models can provide and what local practitioners need; and there is a serious lack of appropriate local information on disaster impacts, as well as information on exposure and vulnerability, the latter of which is especially difficult to define, measure, and monitor [20,21]. This information scarcity severely hampers local risk reduction, preparedness and response, hinders rigorous flood risk modeling and assessment, and compromises global efforts to build resilience of flood-prone communities.

While lack of expertise, technological capacity, and financial resources (i.e., human, physical, and financial capitals) were considered important factors behind such information deficit in developing countries [22], to quickly narrow this gap also demands innovative approaches to engage broader participation from local stakeholders and the general public, and making use of existing resource and tools more effectively.

\subsection{Literature Review: Participatory and Collaborative Risk Mapping Approaches}

Community participatory disaster risk assessment has been considered an effective way to collect disaster risk information, especially on vulnerability, with other benefits such as empowerment and scalability [23]. Vulnerability and Capacity Assessment (VCA) is one of the standard and de facto participatory tools used by humanitarian organizations [24,25]. This largely qualitative participatory approach builds on the methodology of Participatory Rural Appraisal (PRA), which has been widely used in international development to incorporate local community's knowledge and opinions for better planning and managing development projects and programs [26]. VCA expands the tools and methods in PRA (e.g., mapping and modelling, transect walks, seasonal calendars, and analytical diagramming) with additional ones (e.g., household/neighborhood vulnerability assessment). During VCA process, community members are enabled to share and analyze their local and traditional knowledge on both livelihoods and disaster risk, to plan and to act for enhancing their capacities and reducing vulnerabilities to natural hazards.

Among all the PRA/VCA tools, community mapping plays a key role in the participatory process. Mapping helps stakeholders visually representing the biogeophysical characteristics and various resources in a community. In addition to PRA's community social and resource maps, in VCA processes, community members make additional maps to indicate locations of hazards, household, and community assets potentially being exposed to hazards, and socially and/or physically vulnerable households/neighborhoods [25]. The mapping process is highly useful in stimulating discussions among community members. Such participatory map products are expected to improve the understanding of the volume and spatial distribution of a community's resources and capacities 
and provide essential on-the-ground information for the analysis of disaster risks and identification of solutions, such as land use planning (risk reduction), early warning systems (preparedness), and response operations $[25,27,28]$.

Major humanitarian and development organizations and agencies, such as International Federation of Red Cross and Red Crescent Societies [24,25,29], Oxfam [30], and CARE International [31], have used VCAs or similar community-based participatory risk assessments to gather, organize, and analyze information on the locale-specific vulnerability and capacity of communities. Numerous local maps are produced annually around the world, constituting a significant but still underutilized source of local risk information. With the emergence and increasing availability of global positioning systems (GPS), remote sensing and Geographic Information Systems (GIS) resources and techniques, participatory interpretation of aerial photographs, or participatory GIS analyses have been introduced to community-based disaster risk management [32-34]. However, our observations and communications with relevant organizations show that currently most VCA maps are still drawn on paper. These paper maps are not easily replicable or scalable, prone to wear or damage, often not well stored, usually not used after a project finishes, and rarely shared across communities and organizations [32]. The insufficient level of interoperability of the map products, likely due to the lack of relevant capacities and the emphasis on the processes rather than the results, has also limited the potential to fully exploit the value of these maps and other important risk information from VCAs.

Different from participatory mapping, which tends to engage local people and the community, collaborative mapping moves the process to on online environment. Fast development of the internet, cloud storage and computing, broadband communication, social media, and personal locational devices have greatly enhanced the visibility and ease of practices involving the generation and sharing of geographic information by citizens $[35,36]$. Referred to using a range of terms that generally fall under the broader umbrella of user-generated content [37], the contribution of geographic information by citizens can include both active contributions such as mapping or geotagged photographs, i.e., volunteered geographic information (VGI) [35,38], or more passively through social media, e.g., geotagged tweets, referred to as ambient geospatial information [39]. The wide usage of smartphones, with their multimedia capabilities, and increased collaborative potential through social media has provided unprecedented opportunities for individuals to contribute towards and access a collective geographic knowledge base. One of the most prominent open VGI mapping platforms is OpenStreetMap (OSM) [40]. Founded in 2004 with the aim to produce and distribute free geographic data globally, OpenStreetMap has become the most commonly used alternative source for geographic data [41,42].

The application of collaborative mapping to disaster response is also called crisis mapping [43] and digital humanitarianism $[44,45]$. The fast growing Humanitarian OpenStreetMap Team has reached some of the most disaster vulnerable and data scarce regions, such as South and Southeast Asia and Sub-Saharan Africa [46]. For example, in the 2015 Nepal Earthquake, thousands of volunteers from around the world contributed to mapping the surrounding infrastructure such as buildings and roads in Nepal [47]. Humanitarian OpenStreetMap Team relies heavily on the willingness of volunteers, both to contribute entries and to validate the maps through its OSM tasking manager. However, volunteer crisis mapping efforts often decline sharply once the feeling of urgency and crisis diminishes [48]. There is a strong need to further engage citizen mappers to contribute to other stages of the disaster risk management cycle, such as risk prevention and reduction, preparedness, and reconstruction [49]. Furthermore, crisis mapping often only results in crude information on hazard and impacts, and misses important details on exposure of assets and lives, and on vulnerability, especially socioeconomic vulnerability of individuals and groups, at local levels [49], which has traditionally been collected using community-based participatory mapping. 


\subsection{Hypothesis and Objective}

Participatory mapping and collaborative mapping share some of their intentions, principles, and perspectives, while differing in the ways in which these principles are approached, such as the types, depth, and richness of knowledge inputs and ownership and empowerment opportunities [50]. The complementarity of the two approaches seems high, so does the benefit of integrating the two to take advantages of their strengths, especially in the context of disaster risk knowledge (co-)generation in data deficient developing countries.

We hypothesize that by integrating community-based participatory mapping processes with internet-based collaborative digital mapping technologies, it is possible to harness the power of both traditional knowledge and citizen science to improve understanding of disaster risk, especially at local scales. The main objective is to develop and evaluate the integrated mapping approach for effective co-production of knowledge on disaster risks and impacts in developing country contexts, thus supporting disaster resilience building at local and higher levels. A case study in the lower Karnali river basin, Nepal is used to demonstrate the benefit and potential of such mapping processes. Specifically, we aim to support local stakeholders to map pilot communities according to their needs in a GIS environment (i.e., using the OSM geo-spatial platform), and to compile and analyze community risk and capacity information to better assist stakeholders with their flood risk reduction and resilience building planning and implementation. We collected feedback from the participants in this process and further explored the potential to replicate and upscale the approach for enhancing disaster resilience at higher levels.

\section{Materials and Methods}

\subsection{An Integrated Participatory and Collaborative Mapping Approach}

In this study, we developed an integrated participatory and collaborative mapping methodology for the collection and management of local disaster risk information, and the available resources and capacity. A collection of tools was employed from participatory VCAs (e.g., community resource maps, social maps, risk maps, transect walks) and collaborative mapping using the OSM platform (e.g., rasterizing hand-drawn map resources, remote mapping by sketching in features visible from aerial imagery, merging vector datasets into OSM). These activities are accompanied by ground data collection using Field Papers and OSMTracker, offline mapping and data validation using JOSM (Java OpenStreetMap Editor), and customized map making using QGIS. Detailed introductions to the specific tools are provided in the Appendix A. The purpose is to take advantage of the various strengths of the diverse range of tools available in both approaches and involve a wider range of stakeholders and citizens to co-produce the knowledge more effectively and efficiently.

The general procedure includes the following steps:

a Collect and digitize or rasterize existing analog community maps (PRA, VCA, and others), and identify geographic locations of target communities;

b Conduct remote mapping on the OSM platform using both satellite images and community maps and generate preliminary baseline community maps;

c Develop field surveys to fill major data gaps in the preliminary maps together with local stakeholders (e.g., government, NGOs, and communities);

d Organize focus groups with local communities to discuss and further improve the baseline maps;

e Maintain traditional community mapping activities using baseline maps as the basis and add information to capture new changes (e.g., land use changes, impacts from recent disaster events) and discuss risk management options;

$\mathrm{f}$ Store spatial information locally in a GIS (likely by government agencies and NGOs) and upload non-sensitive data to online open platform (e.g., OSM); 
g Monitor changes via OSM as well as ground observation, periodically update the maps, and share and exchange them across communities and with regional stakeholders.

The order of the steps and the use of specific tools in the general procedure was not intended to be strictly enforced. Instead, we suggest that the approach can be implemented in a flexible and iterative manner, suiting specific social, institutional, and technological contexts of the users. While maintaining the strength of PRA/VCA approaches on active conversations and interactions with community members, the integrated approach is designed to be inclusive to more stakeholder types (e.g., community organizations, local NGOs, government agencies, etc.) such that stakeholders and non-stakeholder citizens can flexibly participate and contribute at various stages.

\subsection{Pilot Case Study in Lower Karnali River Basin, Nepal}

We implemented the integrated mapping procedure in the lower Karnali river basin in Western Nepal. Characterized by sharp contrasts in physiography and climate, along with geologically unstable and high-relief mountain topography and intense monsoon rainfall, Nepal is one of the global hotspots for natural hazards, such as earthquakes, floods, and landslides [51]. In the Karnali river basin, intense monsoon rainfall and unstable and steep slopes above the Chisapani gauge station (Figure 1) result in high rates of soil erosion and landslides and a high sediment load in rivers. When the river enters the lower catchment in the flat plains of the alluvial and fertile Terai area, it spreads out into two main branches and deposits large amounts of sand and gravel. Three major floods have occurred in the lower Karnali river basin in the past decade in 2009, 2013, and 2014, respectively. These floods not only seriously disrupt local livelihoods, particularly subsistence agriculture, but also cause widespread damage to lives, assets, and infrastructure [52].
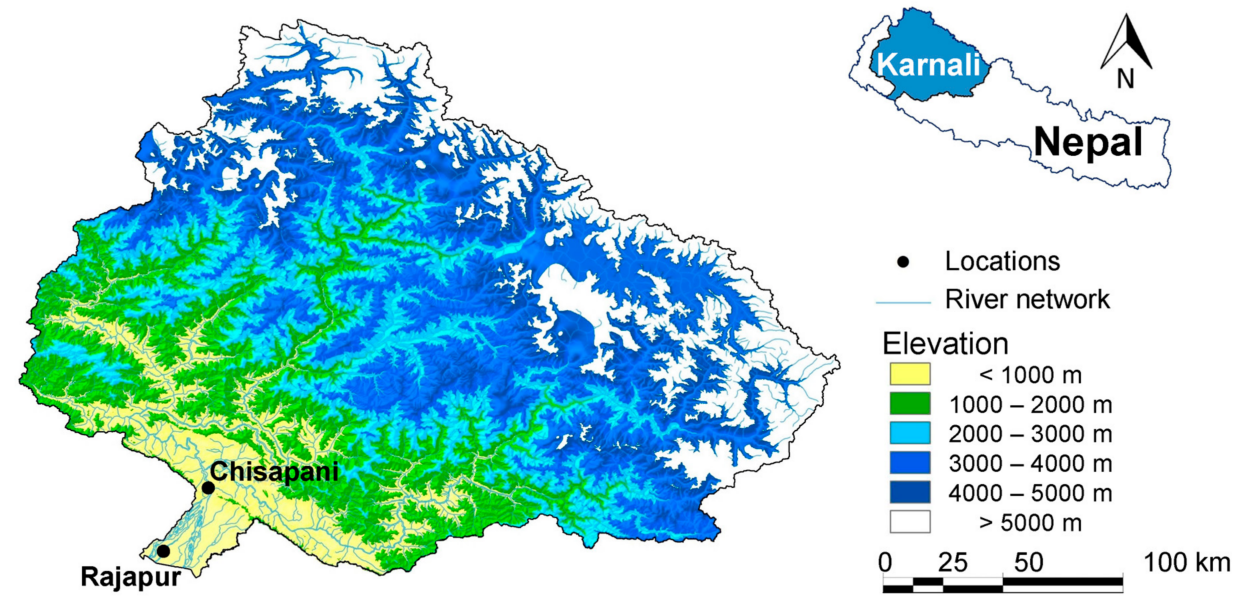

Figure 1. Location of Karnali river basin in western Nepal.

The Zurich Flood Resilience Alliance's Nepal Flood Resilience Program has been implemented in lower Karnali since 2013, involving a total of 74 communities [52]. Here, the west branch of the Karnali River divides the region into Baridya District to the east and Kailali district to the west. Bardiya and Kailali districts together have a population of $\sim 1.2$ million according the 2011 census of Nepal. In the year 2011, Human Development Indices in both districts are between 0.46-0.47, slightly lower than the national value of 0.49 and almost equal to the average value of rural areas $(0.464)$ and Terai areas (0.468) [53]. Life expectancy is between 66-67 and literacy level between 57-59\%, both slightly lower than national average. Adult literacy percentage (57-59\%) was slightly lower than national average $(\sim 60 \%)$. With agriculture and wage labor being top income sources in the region, per capital annual income was 1086 USD in Bardiya (lower than national average at 1160 USD) and 942 USD in Kailali (slightly higher than rural average at 936 USD) [53]. 
Three pilot communities (Figure 2) were selected along the west branch of the lower Karnali river, including Chakkhapur to the southeast and Bangaun and Phanta to the northwest. They were selected as they all suffered extensively from flooding in the past and are relatively close $(\sim 2 \mathrm{~km})$ to Rajapur Rural Municipality in Bardiya District, where most of the Nepal Flood Resilience Program's activities were coordinated locally. Based on the 2011 National Census 52,438 people reside in the municipality and the average household size is about five [54]. The focal community, Chakkhapur, is the largest among the three in terms of area (around 50 ha immediately next to the Karnali river) and has most heterogeneous environmental and socioeconomic characteristics. By 2014, there were 96 households with a total of 645 individuals, of which females and males are roughly $50 \%$ each. The community was frequently struck by floods and it takes about three hours for flood water to reach the community from Chisapani. In the 2013 and 2014 floods, almost all houses and the majority of the land were submerged (Practical Action Nepal 2015). Like many communities in the region, most adult males in Chakkhapur migrate to foreign countries for work, leaving women manage homes, agriculture, and disaster risk [52]. For instance, the Chakkhapur community disaster management committee is headed by a female and most members are females.

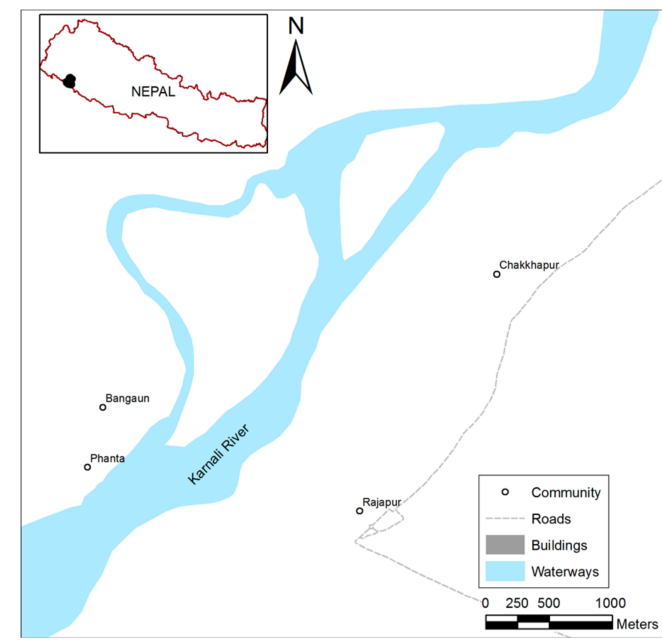

(a)

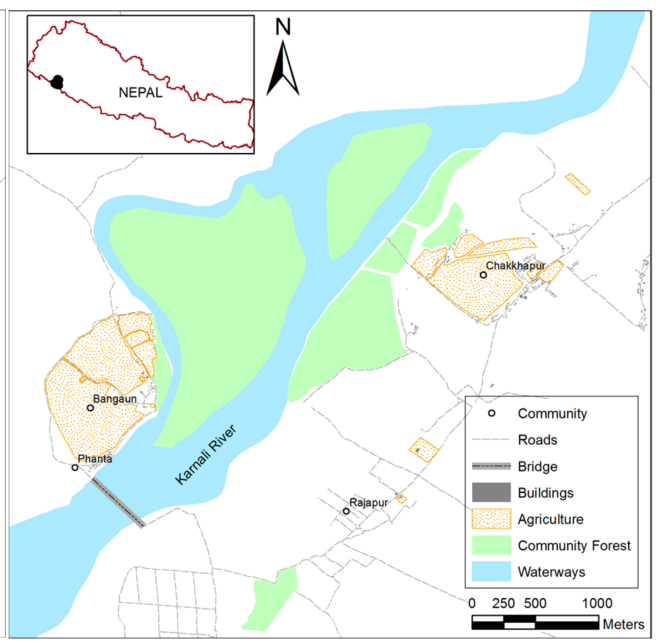

(b)

Figure 2. OpenStreetMap data of the pilot implementation area, showing locations of the three pilot communities and the nearby Rajapur municipality on (a) 1 January 2015 and (b) 1 January 2017. Historical OpenStreetMap data for Nepal (http:/ / download.geofabrik.de/asia/nepal.html\#) is freely downloadable from GeoFabrik and maps were created in ArcGIS. As of early 2015 (a), before this study commenced, almost no ground features were mapped in the study area on the OpenStreetMap platform; by early 2017 (b), many more ground features were mapped in the three pilot communities including a bridge on the west branch of Karnali river.

At the beginning of the Nepal Flood Resilience Program, in the lower Karnali region, no formal data on the flood hazard, exposer, vulnerability, and capacity information existed at levels below the community. Figure 2a shows what the pilot study area looks like on OpenStreetMap as of 1 January 2015; similarly, almost no information could be found on Google Maps in this area, including the location of most communities even until late 2017. The main information source after the 2014 Karnali flood came from regional Red Cross society [52], which play a key role in disaster rescue in collaboration with local government and army. At least partly due to lack of necessary resources and information, flood preparedness and reduction measures in the region were under-developed. As a result, a total of 222 people lost their lives in the 2014 floods and 120,000 others were seriously impacted [52].

As part of the Nepal Flood Resilience Program, Practical Action Nepal started to support 74 lower Karnali communities to establish community disaster management committees before the 2014 
monsoon season [52]. One round of VCAs were conducted by these committees, with facilitation from Practical Action's Karnali regional office to gain first-hand information on flood risk and capacity, in each community from winter 2014 to spring 2015. Facilitated target group discussion in the community was organized with participants inclusive of gender, age, ethnicity, and population. Three maps (i.e., capacity, social, and hazard maps) were initially drawn on the ground and later reproduced on poster paper. These paper maps were digitally photographed, and in early 2016 used as reference to guide standard OSM mapping. Recognizable features were mapped against high resolution imagery provided by Bing through the OSM platform, following general guidelines for remote mapping in Nepal [55]. During a subsequent visit to Chakkhapur in March 2016, a focus group discussion was organized with 14 committee members and two social mobilizers (i.e., local residents recruited by the NFRP to support community projects). Two members and both social mobilizers were males and all others were females. A printed digital map of Chakkhapur overlaid on high resolution satellite imagery from Google Earth was shown against a VCA map painted on the wall. A laptop computer with pre-loaded Google Earth imagery was also shown to the participants. The discussion focused on mapping processes, map contents, and map usage in community flood risk management activities.

In September 2016, a five-day workshop, including a series of indoor and field activities (see Figure 3 for the general workflow), was carried out near Rajapur. Twelve stakeholders, of which three were female and nine were male, participated in this stage, including seven local community social mobilizers and five NGO staff and managers.
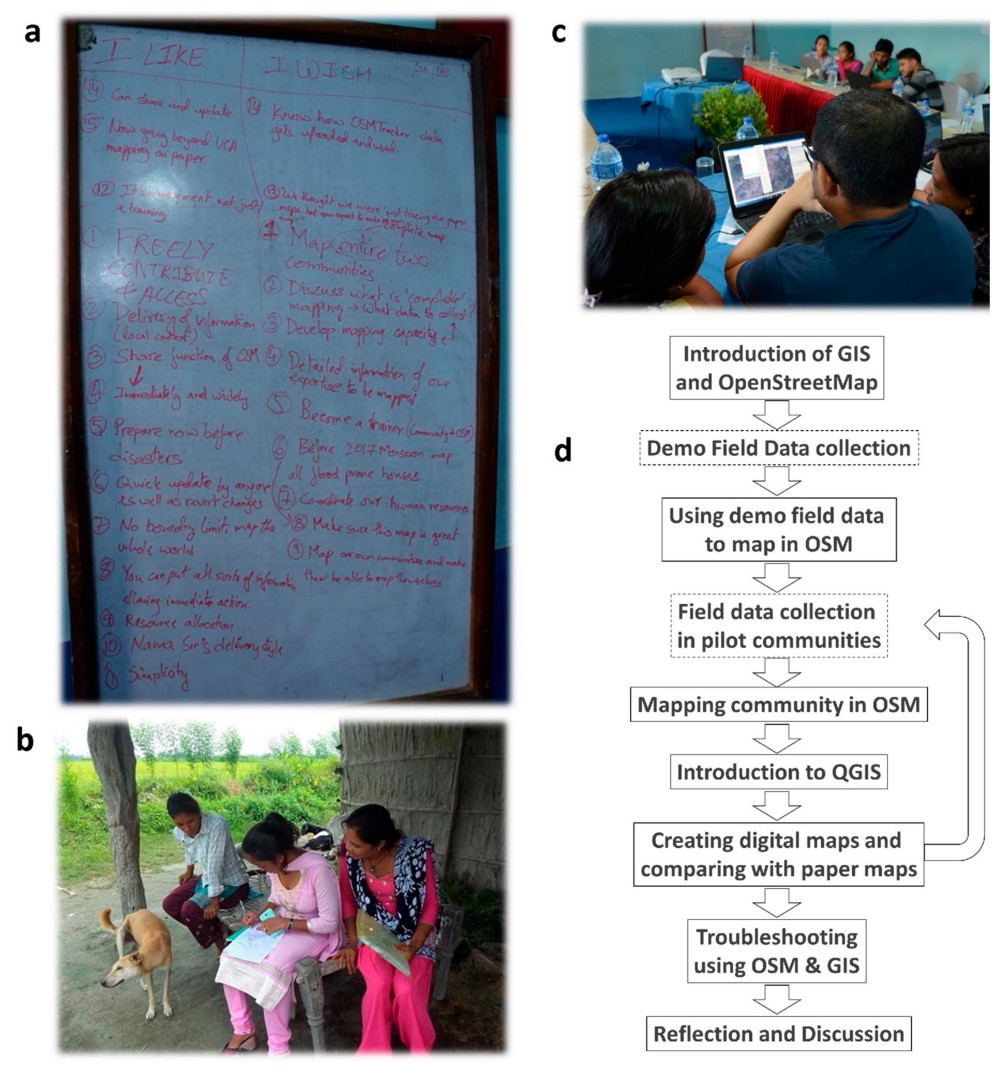

Figure 3. General workflow of the stakeholder mapping procedure; (a) user assessment; (b) volunteers in the field mapping and surveying; (c) volunteers digitizing the collected information; and (d) diagram of workflow (dark grey indicates outdoor activities, while light grey indicates indoor activities).

The participants were not randomly selected; instead, all of them had prior experience working on community flood risk management in the region, and most had participated in or even facilitated 
VCA processes in person. The participants had different levels of computer literacy and only two had prior experience of using GIS. While the NGO managers all had smartphones, two of the seven social mobilizers used feature phones (i.e., phones with less features than smartphones, allowing internet access but not downloading of apps). Smartphone use among the selected stakeholders is higher than community people in the region, where a feature phone is common in almost all households and $~ 10 \%$ of local households own a smartphone as of 2016. Based on personal observations in the field, social media, such as Facebook, Twitter, and WhatsApp, were also used by some community members, local businesses, and local government personnel. The gender percentage and smart phone use rate among this group is close to what we have observed among development work professionals in the region and in Nepal in general.

All three pilot communities were mapped, including locations of all houses (including independently constructed units such as kitchens and livestock sheds) and key infrastructure (e.g., emergency shelters, community health posts, drinking wells, and culverts). In the focal community Chakkhapur, the team surveyed 65 out of the 96 households, where at least one household member was available to identify the flood level during the most recent flood event (in 2014) on the walls of their houses. This self-reported flood level and the observed level at which the same house was elevated were measured using a measuring tape. Data collected were used in the later indoor activities to map the communities in the OSM platform and to create customized community maps for comparison with the hand-drawn VCA maps.

At the end of the workshop, a one-hour facilitated discussion was organized, during which the participants provided individual reflection and feedback and discussed gaps and challenges for upscaling the pilot efforts to more communities. The discussion was partially transcribed and later translated into English.

To maintain this collaborative relationship, a Facebook group was established in early 2017 to further facilitate communication with the workshop participants to provide support for practicing the new techniques and to learn about local needs, concerns, and progress. Further efforts to upscale the practice in lower Karnali are ongoing, including two mapathons organized in March 2017 to engage citizen volunteers to remotely map more communities [56].

All spatial data in this study were collated and maps were generated using ESRI ArcMap 10.1 (Redlands, CA, USA). All quantitative data were organized in Microsoft Excel 2016 and statistical analyses were conducted in IBM SPSS Statistics 24 (New York, NY, USA).

\section{Results}

The main results include new maps showing hazard, vulnerability, and capacity at both household and community levels, especially highlighting their spatial heterogeneity, and feedback from the workshop participants.

\subsection{Comparison of Map Content}

Figure 2a,b show the study area in OSM as of January 2015 and January 2017, respectively. Clearly visible is the lack of roads and buildings in Figure 2a. Significantly more features were added into OSM in 2016, exclusively by the stakeholders themselves in the context of this study, including a new bridge (near the Phanta and Bangaun communities to the west of Rajapur) that was finished in 2015. A comparison with Google Maps as of November 2017 also confirms that almost no buildings were included by Google for this area (Figure 4a,b). Hence, the data now provide the only comprehensive, openly accessible spatial information available for lower Karnali river basin. 


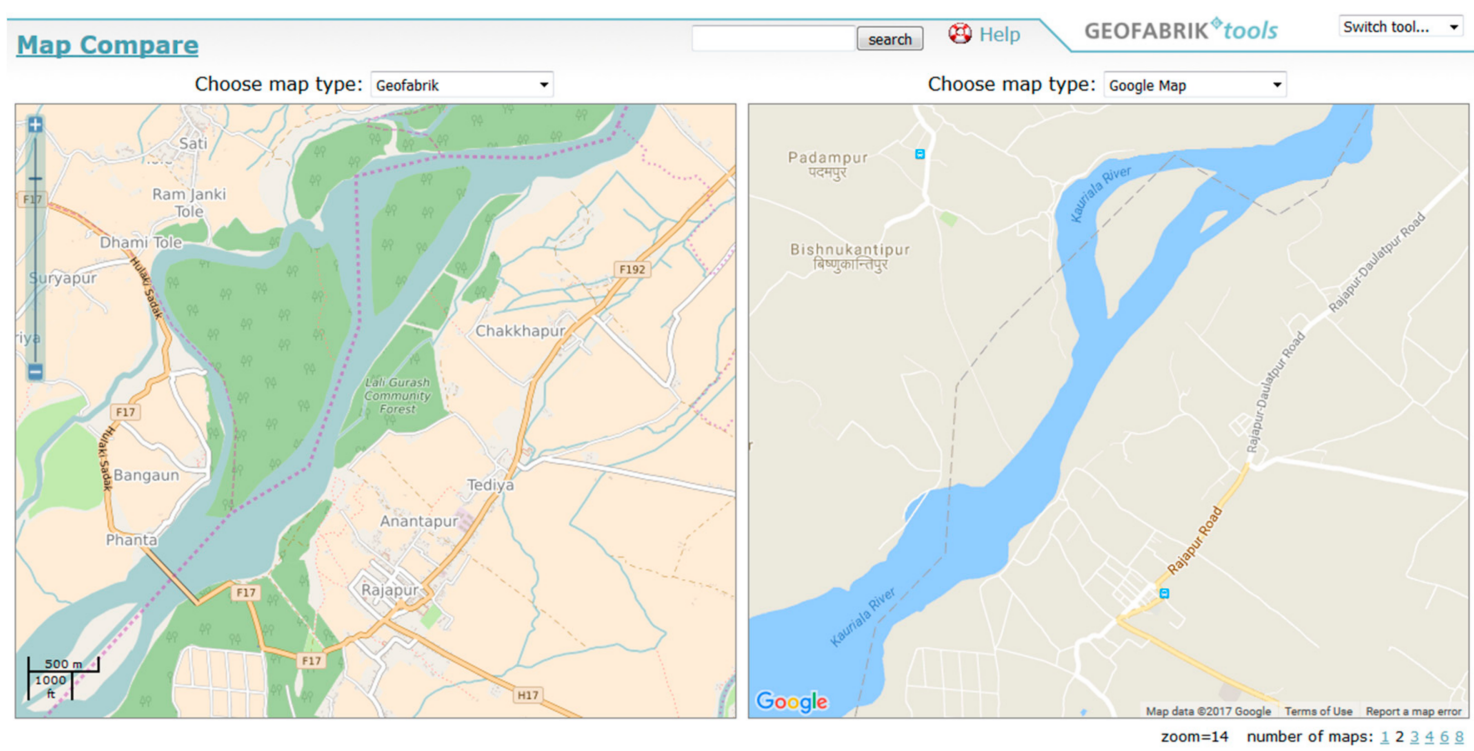

(a)

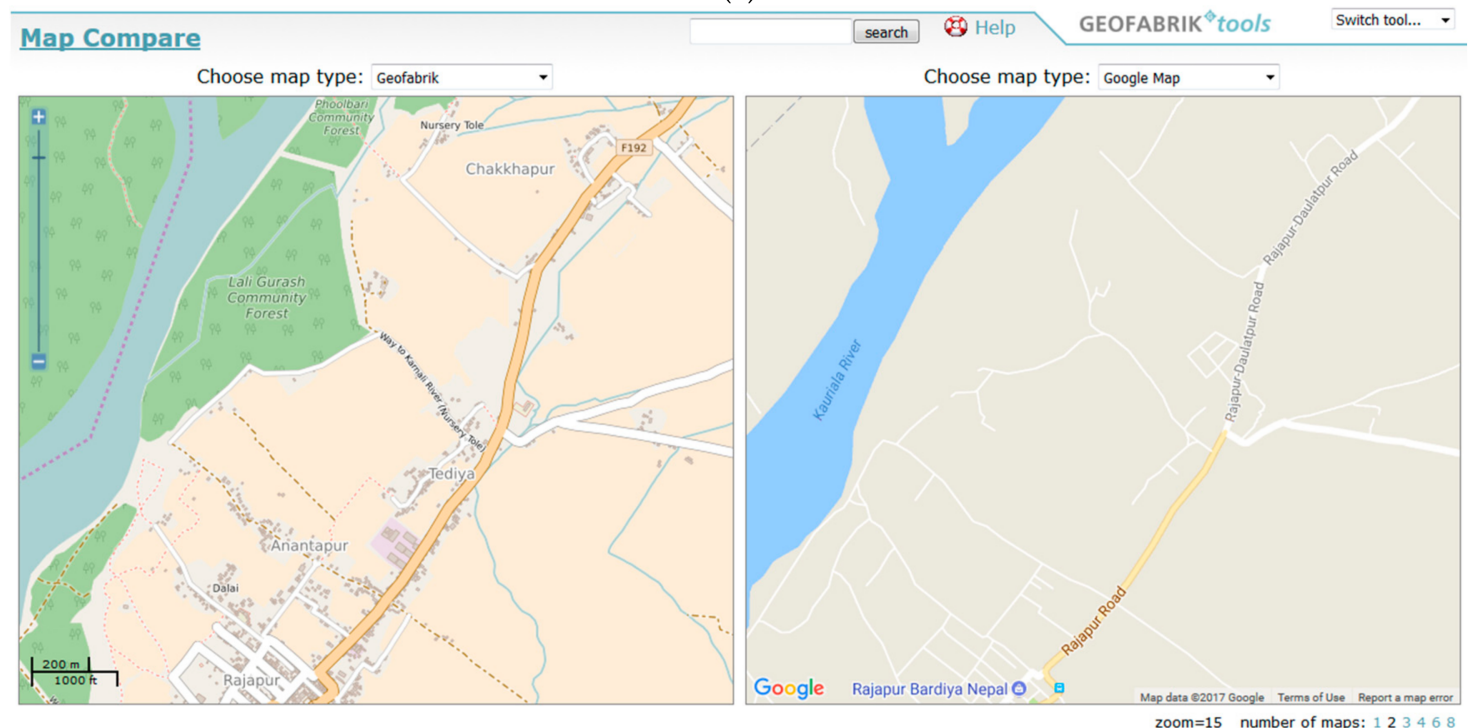

(b)

Figure 4. Screenshots from GeoFabrik's Map Compare tool showing side-by-side comparison of OSM and Google maps (as of November 2017) for: (a) the pilot implementation area; and (b) a zooming-in view of Chakkhapur community to Rajapur municipality area (note that many features such as shelter and health posts are not shown in OSM at this zooming level).

Using Chakkhapur as an example, Figure 5a-d shows the hand-drawn VCA maps created by the community and an equivalent map created using information generated during the mapping processes of this study. VCA results showed that as of January 2015, there were four disabled persons, eight pregnant women, seven lactating mothers, and 33 elderlies (60+ years old) in the community. Based on discussions with workshop participants, features related to this detailed confidential information of socially vulnerable households were shown as NA in Figure 5a-c and not specifically labeled in Figure 5d. 


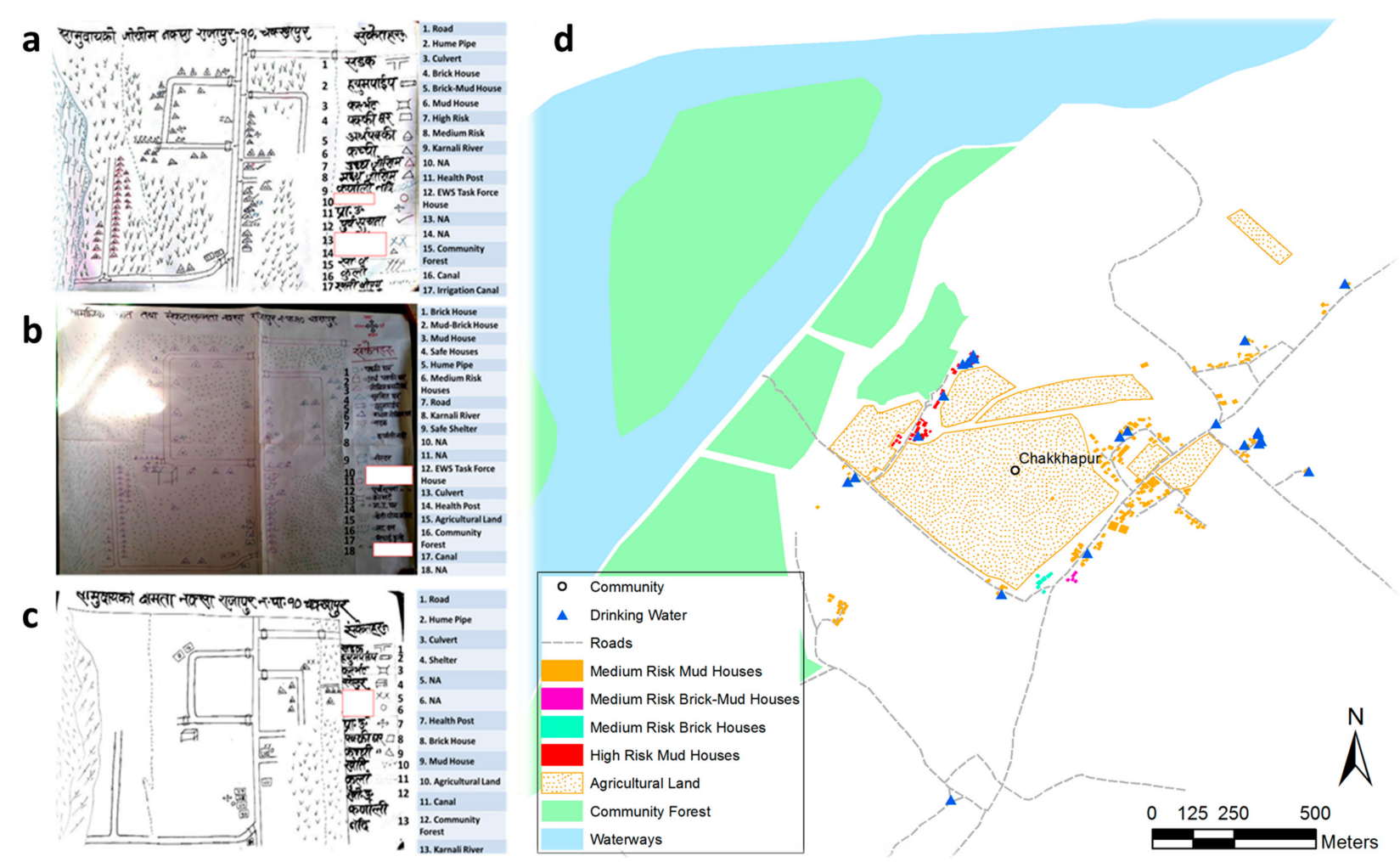

Figure 5. Chakkhapur community (a) risk map, (b) capacity map, (c) social map (a-c) are photos of sketch paper maps), and (d) digital map produced using the information entered into OSM during the course of this study, merged with data available from the community VCA maps. 


\subsection{The Spatial Pattern of Flood Hazards and Vulnerability at the Community Level}

Besides a better visual representation of the community, further analysis provides more insights into the heterogeneity of flood hazards, vulnerability, and impacts among households. Self-reported flood levels and the measured level of house elevation above the ground of 65 households surveyed in Chakkhapur are shown in Figure 6. The flood level shows a clear pattern as would be expected-the cluster of houses near the river (distance $<1 \mathrm{~km}, n=20$ ) experienced higher flood levels (Mean $\pm \mathrm{SD}=110.0 \pm 37.8 \mathrm{~cm}$ ) than the other cluster that is further away from the river (distance $=2-3 \mathrm{~km}, n=45$, Flood Level $=56.4 \pm 30.9 \mathrm{~cm}$ ). However, a significant proportion of houses in the former cluster were not elevated (HH elevation level $=25.5 \pm 23.1 \mathrm{~cm}$ ), a commonly used method to reduce the physical vulnerability of houses, and thus are still prone to high flood risk. Most houses in the latter cluster were not substantially elevated ( $\mathrm{HH}$ elevation level $=21.0 \pm 19.5 \mathrm{~cm}$ ) either (Figure 6). A subset of houses in the latter cluster near the main road and Rajapur were constructed with bricks or mixture of bricks and mud, making them much less physically vulnerable than all other mud-and-thatch-constructed houses in the community (Figure 4d).

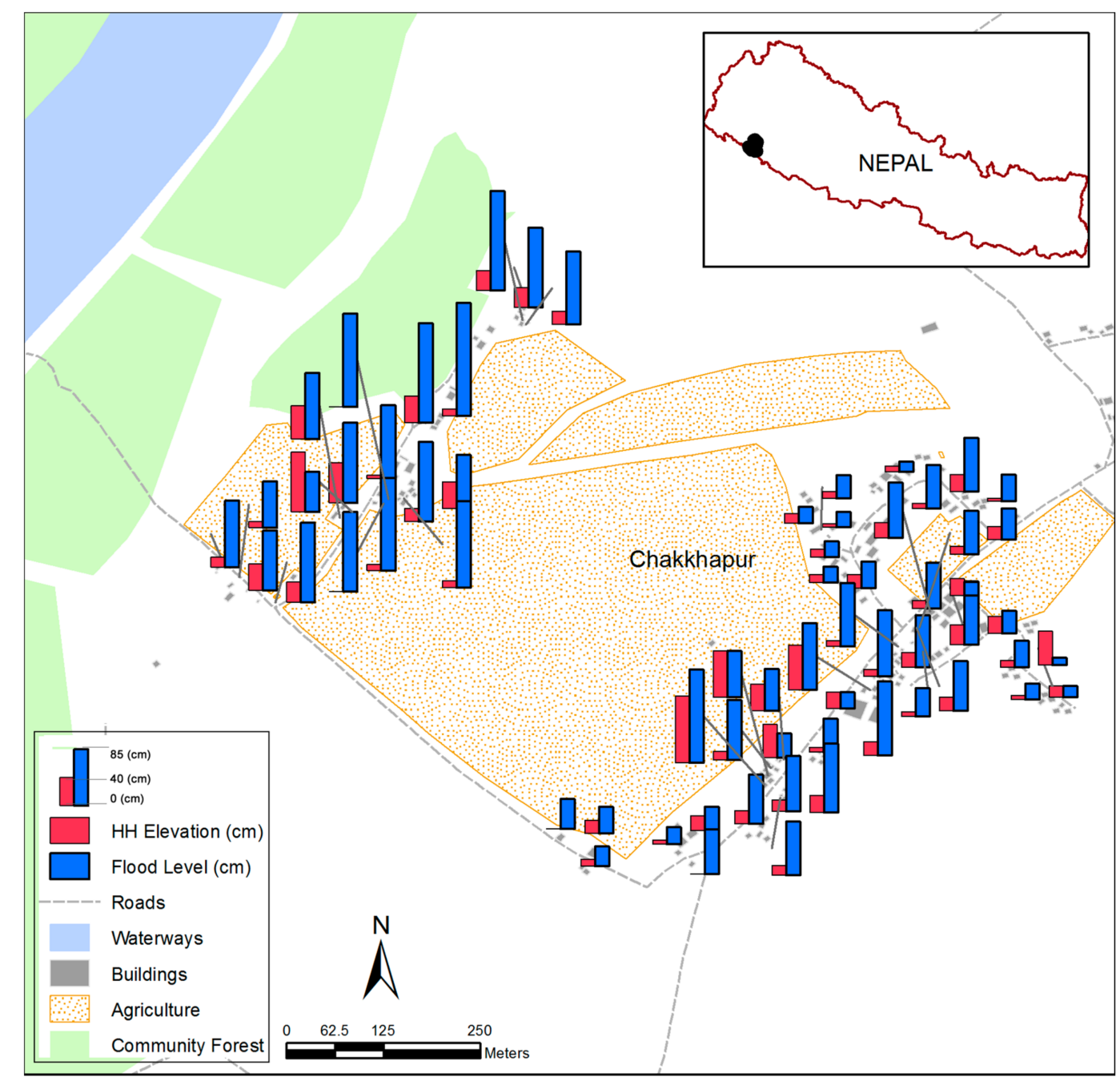

Figure 6. Flood hazard and physical vulnerability map of Chakkhapur. Heights of the bars correspond to self-reported flood levels (in cm) in August 2014 at house locations and measured level (in cm) of elevated houses $(n=65)$. The background map is from OpenStreetMap. 
Mann-Whitney U Test results (Figure 7) show that the difference in the flood levels between the two clusters of households is statistically significant $(p<0.001)$, but there is no significant difference in the house elevated levels $(p=0.531)$. The hypothetical house submergence level is the flood level after subtracting the house elevated level, which is set to zero if the former is lower than the latter, indicating the severity of the situation should a flood at a similar level to the 2014 one occur. In terms of this hypothetical house submergence level, the difference is also statistically significant $(p<0.001)$. The results clearly show a high level of spatial heterogeneity within the community in terms of household social (Figure 5a-c) and physical vulnerability (Figures $5 \mathrm{~d}$ and 6 ).

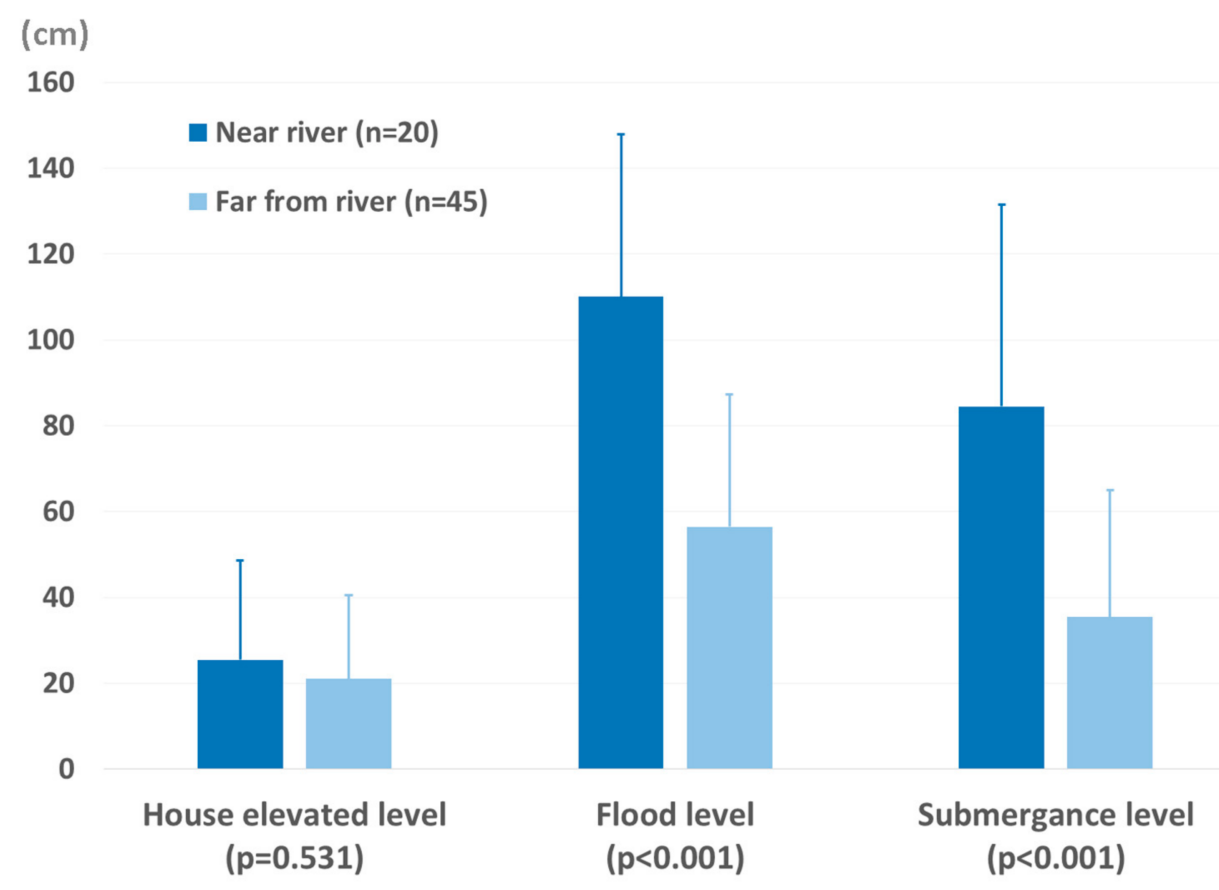

Figure 7. Comparison of Chakhapur households near the river and far from the river in terms of flood hazard (self-reported flood level), physical vulnerability (house elevated level), and potential impacts (submergence level). The error bars show the standard deviations of each measurement.

\subsection{Observations and Stakeholder Feedback}

During the initial focus group with Chakkhapur community disaster management committee members, the digital map was enthusiastically accepted, based on our observations and later discussions with the two social mobilizers. They could quickly navigate around the landscape, identify specific locations and features, and describe what happened during the past flood events with detailed spatial information (e.g., the location where water first entered the community and areas that were submerged for extended periods). They also pointed out some errors (e.g., land use changes after the date of the satellite imagery) and suggested changes and additional features (e.g., health posts) for improving the map.

During the workshop, stakeholder participants showed strong interest and motivation to learn digital and remote mapping techniques. Moreover, since the participants all worked together to some extent, there was a high level of interaction between them. During data collection in the pilot communities, the group also interacted with each community disaster management committees and some local households, most of whom appeared to be interested in these digital mapping activities. All participants were well engaged with both the indoor and field activities and discussed the potential for mapping in more communities using mobile phones and computers. Overall, the participants preferred the participatory and collaborative digital mapping processes and results over conventional VCA mapping processes. 
Pros and cons of the new and conventional approaches were discussed at the end of the workshop. While acknowledging that paper maps are easy to draw, robust to technology failure and friendly to technologically disadvantaged group (e.g., elderlies), they also pointed out that in practice it was not always easy to have broad participation in conventional VCA mapping processes and contribution often came from a small number of members; specific groups, often youths and females, could be marginalized. They also mentioned that the resulted paper maps were easy to be worn, difficult, and costly for using in the field and updating new changes, and hardly can be linked, partly due to lack of standardization and spatial accuracy. They liked the capacity of the digital maps to include richer and spatially finer contents (e.g., heterogeneity in the physical and socioeconomic conditions of households, as shown in Figure $5 \mathrm{~d}$ and their changes) and the fact that the resulted maps can be more widely distributed and more easily edited, updated, and shared by broader community members and stakeholders outside communities. They also discussed how the approach may effectively help involving marginalized groups, as it is open and convenient to contribute outside the formal VCA processes.

The participants also raised several concerns about the adoption of the new processes, such as the potential exclusion of technologically disadvantaged elderlies (who often possess rich knowledge about past disaster events), limited capacity for communities to administrate the processes, and unstable local accessibility to power and the internet in Western Nepal. Other issues that the participants mentioned include who owns the maps, what types of content to map, and how the new mapping processes may be useful and applied in broader community issues besides flood risk management.

The participants' enthusiasm for digital and remote mapping, and the desire to continue these activities, are reflected in their final statements (see selected quotes in Table 1). More importantly, the social mobilizer group decided to organize regular mapping parties following the workshop. Remotely supported by Nepal Flood Resilience Program staff, researchers, and volunteers, more communities in the region have since been remotely mapped.

Table 1. Quotes from final statements of selected participants.

\begin{tabular}{ll}
\hline \multicolumn{1}{c}{ Individual } & \multicolumn{1}{c}{ Title 3 } \\
\hline A. Social mobilizer, Female & $\begin{array}{l}\text { "We can map all the shelter locations and resources now. In addition, we can easily } \\
\text { share this information with other organizations as well. Before it was cumbersome } \\
\text { to show VCA maps and explain the work we did. Now, I think it will be easier to } \\
\text { explain the work we have been doing." }\end{array}$ \\
\hline "Before we used to just bring data, but now we bring it then share it with the whole \\
world. We also spend a long time processing the work once we collect data, this \\
was challenging but rewarding in its own way."
\end{tabular}




\section{Discussions and Conclusions}

\subsection{Local Risk Information Generation and Management for Community Disaster Resilience}

Building disaster resilience requires a paradigm shift from the over-reliance on top-down expert-led risk information production to a more integrated and polycentric knowledge generation scheme [6,22]. The Sendai Framework also called for "inclusive risk-informed decision-making based on the open exchange and dissemination of disaggregated data ... as well as on easily accessible, up-to-date, comprehensible, science-based, non-sensitive risk information, complemented by traditional knowledge" [8]. A variety of new knowledge services are needed to meet the priorities established under the Framework. Local and traditional knowledge, such as community participatory mapping, and open and citizen science, such as internet-based collaborative mapping, are essential parts of the necessary knowledge base for spatial risk information. By integrating participatory and collaborative mapping, our new approach can help efficiently capture people's valuable, but often non-documented, spatial knowledge, that complements authoritative sources of information, with higher spatial resolution and accuracy, richer contents, and better interoperability.

In the Karnali case, local spatial risk information provided useful details for a better and more nuanced understanding on how household-level flood hazard, exposure, and vulnerability interact, and led to the emergence of community-level patterns of disaster risk and impacts. For example, flood level information shown in Figure 6 shows a clear spatial pattern of higher flood hazard with proximity to the river. Within the cluster of households further away from the river, it seems that houses near the main road experienced higher flood levels than the others, possibly because water conduits, such as ditches and tunnels, are more densely distributed along the main road. Spatial heterogeneity of social vulnerability information (e.g., disabled, elderly, and pregnancy) across households are captured in paper maps (Figure $5 \mathrm{a}-\mathrm{c}$ ), and these can be easily recorded in GIS for use by CDMC and other local organizations and stakeholders.

Spatial heterogeneity of household-level physical vulnerability is evident from Figure $5 \mathrm{~d}$ (mud vs. brick houses) and Figure 6 (house elevated levels). Most households in the more hazardous riverside cluster did not elevate their houses to a level high enough to completely prevent inundation (Figure 5d). This may be due to both the households' lack of resources and the fact that mud houses can be rebuilt with local resources relatively easily and quickly; thus, these households seem to be able to build back to the same but not building back better. During the household visits, we also noticed that many households chose to elevate grain storage inside houses by up to one meter, a practice now more widely implemented after the 2013 flood that washed a large amount of stored grains [57]. Costing substantially less than elevating a whole house, this strategy significantly reduces the vulnerability of a critical household asset to flood inundation. Information like this is can also be added as a feature to mapped households to further understand the multi-dimensionality of household-level vulnerability and capacities to inform the design of local resilience building interventions.

The integrated mapping approach can contribute in different ways to building critical capacity of local stakeholders and communities for enhancing their disaster resilience. Different from crisis mapping, which focuses on disaster responses, the integrated approach aims to facilitate the stakeholders to develop a routine of mapping that fit their specific contexts, such that georeferenced local information can be collected and updated throughout disaster risk management cycle iteratively. The mapping process is valuable for improving stakeholders' human and social capital. In our case, many workshop participants reported improved knowledge and skills in spatial mapping and understanding of risk (i.e., improved human capital) and saw the additional advantage of sharing maps across and within communities and among stakeholders (i.e., potential in improving social capital). The enhanced spatial information and improved mapping capacity will support community land use planning. For example, people and assets (human and financial capitals) can be better mobilized to reduce exposure to hazards, and irrigation systems and embankments (physical capital), as well as natural wetland and forests (natural capital), can be better managed for supporting livelihood and 
reducing disaster risk. Together, these improvements will enhance communities' capacity to better prepare for disasters and build back better afterwards, thus being more disaster resilient.

The flexibility and iterative nature of the multi-stage processes, the high level of stakeholder and citizen participation, and the increased interoperability of the risk information products make it possible to replicate and up-scale the integrated mapping procedure. Following this initial pilot, more activities to map more communities across lower Karnali was started in summer 2017. A broader range of stakeholders, such as the local government, the local chapter of the Red Cross Society, and the nearby Bardiya National Park conservation program, were trained, and more than 15,000 buildings in lower Karnali had been remotely mapped by volunteers by the end of March 2017 [56]. This number has increased to 50,000 by August 2017, while local stakeholders are working on validating the mapped information and adding more details. One goal is to provide new digital maps (initially in printed version) to all communities in lower Karnali. These maps, once being fully integrated, will substantially improve existing knowledge on flood risk and resilience at the basin scale. Such knowledge can be further linked with information from other sources (e.g., socioeconomics, natural resources, land uses) to inform broader environmental and development programs. Further rigorous investigation on how the communities perceive and use the maps will be needed to fully understand how this integrated mapping approach can help transforming disaster risk management and building resilience of the communities.

\subsection{Limitations and Future Recommendations}

While the preliminary outcome from the pilot case in lower Karnali river basin is promising, some limitations of the integrated approach should also be noted, such as technological barriers, map ownership, and potential marginalization of specific groups, many of which are not uncommon to either participatory mapping or collaborative mapping [32,35,48,50,58,59].

The integrated mapping approach does involve the use of specialist tools and an understanding of GIS concepts, and is therefore challenging for use by some organizations and communities in the least developed countries. The necessary level of mapping technological literacy and map administration capacity required for communities and organizations may hamper the quick uptake of such processes. This calls for identification of appropriate stakeholder groups to initiate the process and selection of tools commensurate with stakeholders' experience and capacity. In the Karnali case, we identified the local NGO and their social mobilizers as the stakeholder group to start with, because this group had basic GIS awareness and smartphone use experience. While currently local communities in Karnali generally still do not have enough capacity to administrate this process by themselves, in a recent regular meeting held between CSDR and Chakkhapur community, the Chakkhapur CDMC expressed strong willingness to learn and include the new approach in their next VCA process in addition to conventional ground and paper mapping. More stakeholders, such as local government and Red Cross chapter, are now involved in the upscaling stage, as introduced earlier. Building the mapping capacities for stakeholders might take time, but the potential benefits outweigh its costs, as indicated in the feedback of the participating stakeholders (e.g., Table 1), who had learned rapidly and progressively through the processes. Moreover, in general, the technology required for both approaches is becoming more accessible [50], thus there are reasons to be optimistic about the technological enabling environment of applying the integrated mapping approach.

Limited by the preliminary nature in the Karnali case, we could not fully evaluate the empowerment potential of the integrated mapping approach, an important and highly debated topic in both participatory and collaborative mapping literature [58,59]. We try to make the process flexible and iterative so that in practice, more stakeholders can be involved in some, if not all, stages. Specifically, to enhance ownership of the mapping process and products, we started the training workshop with a user assessment (Figure 3a) by asking the participants to report their aspirations and expectations, as well as specific contents that they considered important to map. These were fully considered in the follow-up data collection stage(s). The ongoing upscaling activities are now mainly 
operated by the stakeholders especially in terms of deciding which specific information to validate on the ground, update to the OSM platform, and include in new maps provided to communities. This local-NGO-led program was recently selected by the World Meteorological Organization as a practical youth-led example of advances in the integrated approach to flood and drought risk management [60].

A digital divide $[59,61]$ has been mentioned by stakeholders as a potential issue induced by the new mapping processes. Experience has shown that the introduction of digital technology in participatory and collaborative mapping approaches could both widen and narrow the digital divide [50]. Elderlies in the pilot communities were reported to be less familiar with mobile phones and the internet, thus in theory would be prone to marginalization when digital technology is introduced to mapping. However, the process is currently designed in a way to enhance instead of replacing the existing VCA processes-thus, this and other similar groups (e.g., females) have opportunities to participate in multiple stages (such as a, c, d, and e as shown in 2.1). We suspect what may happen in practice, once the approach is fully implemented with some communities, is that some other groups, especially the youth who used to be marginalized in conventional PRA/VCA processes, may be able to participate more. It will be worthwhile to carefully monitor the resulted changes in power dynamics in mapping and other related activities in the future (e.g., whether a more diverse and balanced participation is realized, and whether some group, such as older females, could be further marginalized). We will continue work in Karnali to explore further the potential of the integrated approach in improving accessibility, dissemination, and use of collated spatial risk knowledge, and empowerment opportunities for local communities and citizens.

At a higher level, mobile network and smart phones penetration increased rapidly in Nepal, including Karnali region. As of September 2017, the mobile phone and internet penetration rates in Nepal had reached $132 \%$ and $62 \%$, respectively, and $98 \%$ of internet users subscribed to the internet via mobile network [62]. Internet users across Nepal more than doubled from 30\% in 2010, mainly through mobile networks, and the launch of a 4G service in summer 2017 in Kathmandu and Pokhara and the recent expansion to around the country, including Karnali river basin, will likely further boost this trend [63]. The improvement in the mobile internet availability and accessibility will provide important technical enabling environment for more stakeholders to learn and use techniques such as integrated risk mapping, helping to fill the critical spatial risk knowledge gap, and may further transform disaster risks management and development planning in areas like Karnali river basin.

The need to improve local disaster risk information generation has been recognized by the broad humanitarian and development sector, including IFRC (Pers. Comm. IFRC 2016). Similar attempts to produce digital VCA maps are currently being tested in the Philippines by the Norwegian and Philippine Red Cross Societies to improve capacity, emergency, and post-emergency mapping via a cloud-based GIS system with uploading, analysis, and decision-supporting functionality. The IFRC have also recently started to build a global repository of VCA reports, including maps, across its member countries (Pers. Comm. IFRC 2017). Systematic investigation and syntheses of these projects can help further develop local risk mapping methodologies and tools and better integrate them into in disaster resilience building and the broader development programs.

Acknowledgments: This study was supported by the Zurich Flood Resilience Alliance funded by the Zurich Foundation. The funder was not involved in study design; in the collection, analysis and interpretation of data; in the writing of the report; and in the decision to submit this article for publication. We would like to thank Buddhi Kumal and Lok Pokharel for logistic support and also for providing valuable information on VCA practices in Karnali communities as well as Nirab Pudasaini and Megha Shrestha for their efforts in facilitating the workshops and providing the training to the stakeholders. We acknowledge the valuable participation from the local stakeholders, including social mobilizers and CDMC members. We would like to thank Jeff Franklin, Bruno Haghebaert, Don Josef, Ian O'Donnell, Lucia Robles, and Marjorie Sotofranco from the International Red Cross and Red Crescent Society (IFRC) for providing valuable information regarding VCA practices in IFRC and Dinanath Bhandari, Peter Burek, Adam French, Stefan Hochrainer-Stigler, Adriana Keating, and Colin McQuistan for providing valuable comments and suggestions during this study. 
Author Contributions: Wei Liu and Sumit Dugar conceived and designed the study; Wei Liu, Sumit Dugar, Gaurav Thapa, Prakash Khadka, Nama Budhathoki and Puja Shakya carried out field work in Karnali river basin, Nepal; Wei Liu, Sumit Dugar, Ian McCallum, Gaurav Thapa and Prakash Khadka analyzed the data; all authors together wrote the paper.

Conflicts of Interest: The authors declare no conflict of interest. The founding sponsors had no role in the design of the study; in the collection, analyses, or interpretation of data; in the writing of the manuscript, and in the decision to publish the results.

\section{Appendix A. Tools Used in the Participatory and Collaborative Mapping Procedures in the Pilot Study in Lower Karnali River Basin, Nepal}

A number of remote and field mapping tools are used in this study to explore the spatial dimensions of the community, the households, and the physical environment and enable people to visualize various features and hazard, resources, capacities, and vulnerability. Due to space limit, specifics about these tools was not described in Section 2. Here, we give a brief introduction of each tool, including references where further details about each tool can be found.

\section{(1) Capacity/Resource map}

Description: Capacity/Resource map is a tool to help learn about community capacity and resource base in terms of the occurrence, distribution, access to, and use of resources; topography; and activities of a community from the perspective of community members. In PRA, the purpose is more about understanding local perceptions of resources than making the map accurate. The participants draw the content according to what is important to them and the objective is to learn local perception of what resources are available and how they are used. In VCA, key infrastructures for disaster response and preparedness, such as shelter, as well as location and building codes of local households, are usually also included. These constitute important layer of information on physical vulnerability or coping capacity of the households and community.

References:

- $\quad$ PRA Tool: Resource Map, in Sontheimer, S., Callens, K., \& Seiffert, B. (1999). Conducting a PRA Training and Modifying PRA Tools to Your Needs-An Example from a Participatory Household Food Security and Nutrition Project in Ethiopia. Rome, Italy: Food and Agriculture Organization of the United Nations—http:/ /www.fao.org/docrep/003/X5996E/x5996e06.htm\#6. 2.1.\%20Resource\%20Map

- IFRC. (2007). VCA toolbox with reference sheets. Geneva, Switzerland: International Federation of Red Cross and Red Crescent-http:/ / www.ifrc.org/Global/Publications/disasters/vca/vcatoolbox-en.pdf

- World Bank (2005). Community Resource Mapping, in Poverty and Social Impact Analysis Sourcebook-http:/ / siteresources.worldbank.org/EXTTOPPSISOU / Resources/14240021185304794278/4026035-1185375653056/4028835-1185375678936/4_Community_resource_ mapping.pdf

\section{(2) Social map}

Description: A social map is to show spatially the social and economic variations (e.g., gender, education, age, wealth, etc.) across households in a community. The objectives are to learn about who lives where in the community, to view the social structures in a community and socioeconomic differences among the households from a spatial perspective, to identify different social groups using locally defined criteria and assess the distribution of assets across social groups, and to learn about the social institutions and the different views local people might have regarding those institutions. Some of these information are essential in VCA to understand the socioeconomic vulnerability of households and neighborhoods within a community, as well as the exposure of lives and assets to potential hazards.

References" 
- $\quad$ PRA Tool: Social Map, in Sontheimer, S., Callens, K., \& Seiffert, B. (1999). Conducting a PRA Training and Modifying PRA Tools to Your Needs-An Example from a Participatory Household Food Security and Nutrition Project in Ethiopia. Rome, Italy: Food and Agriculture Organization of the United Nations-http:/ /www.fao.org/docrep/003/X5996E/x5996e06.htm\#6.2.2.\%20Social\%20Map

- IFRC. (2007). VCA toolbox with reference sheets. Geneva, Switzerland: International Federation of Red Cross and Red Crescent—http:/ /www.ifrc.org/Global/Publications/disasters/vca/vcatoolbox-en.pdf

- World Bank (2005). Social Mapping, in Poverty and Social Impact Analysis Sourcebook-http: / / siteresources.worldbank.org/EXTTOPPSISOU / Resources/1424002-1185304794278/40260351185375653056/4028835-1185375678936/3_Social_mapping.pdf

(3) Hazard/Risk map

Description: A hazard map is a map of a community that identifies the spatial pattern and temporal trend of hazards (e.g., river flood, landslide) and the places and the buildings (e.g., houses, schools, health facilities) that might be adversely affected by the hazards. The production of a hazard map requires consulting with people and groups of varying experience and expertise to gain knowledge on areas and features at risk within the community. By overlaying hazard map with capacity/resource map and social map, stakeholders can identify risk distribution, which facilitates communication and discussion on possible ways to prepare for and reduce risk. This process is an effective way to raise risk awareness and the discussion results are key for community disaster risk management decision making.

References:

- IFRC. (2007). VCA toolbox with reference sheets. Geneva, Switzerland: International Federation of Red Cross and Red Crescent—http://www.ifrc.org/Global/Publications/disasters/vca/vcatoolbox-en.pdf

- World Bank (2005). Risk Mapping, in Poverty and Social Impact Analysis Sourcebook-http: / / siteresources.worldbank.org/EXTTOPPSISOU/Resources/1424002-1185304794278/40260351185375653056/4028835-1185375811087/1_Risk_mapping.pdf

(4) Transect walk

Description: A transect walk involves walking through the community along a give transect to observe and get an overall view of the people, the surroundings and the resources. It is used to show the location, topography, distribution of resources, features, landscape, major land cover, and land uses; and to understand inter-relationships between human activities and settlement patterns and their natural surroundings. It is suitable for assessment to get a big picture on the issues and capacities in a community, and can be used in evaluation stage to detect changes. It is usually most effective when being accompanied by knowledgeable community members.

References:

- IFRC. (2007). VCA toolbox with reference sheets. Geneva, Switzerland: International Federation of Red Cross and Red Crescent.

- World Bank (2005). Transect Walk, in Poverty and Social Impact Analysis Sourcebook-http: / / siteresources.worldbank.org/EXTTOPPSISOU / Resources/1424002-1185304794278 / 40260351185375653056/4028835-1185375678936/1_Transect_walk.pdf

(5) Remote mapping/Armchair mapping

Description: Remote mapping, or armchair mapping, means contributing to OpenStreetMap without leaving your chair. Remote mapping contributions do not involve a surveying phase where the user physically visits the place they are mapping. Instead, a remote mapper contributes through 
manual interpretation of available data sources by sketching in features visible in aerial imagery, rasterizing paper maps (e.g., hand-drawn PRA/VCA maps), merging vector datasets (e.g., OSMTracker data) into OSM, or manual interpretation of notes reports (e.g., notes from field papers). While it is not always considered a good idea to map without looking at the real world, it could be less controversial and become quite useful when coupled with field surveys and crowd-sourced photos from the area to be remotely mapped.

References:

- OpenStreetMap Wiki, Armchair mapping_http://wiki.openstreetmap.org/wiki/Armchair_mapping

- HOTOSM, 2015, HOT Remote Response Guide-http://learnosm.org/files/remote-mapping_en.pdf

(6) Field Paper

Description: Field Papers is a web-based tool to help users create a page layout for multi-page atlas of communities to be mapped. It comes with options to choose various map styles, such as satellite imagery or OpenStreetMap, and built-in note annotation tools with GIS format downloads. A printed atlas can be used in field survey to record notes and observations about the community. Finished survey paper with sketches and notes in the field can be photographed or scanned for upload or storage. The surveyed information can be added into OSM database, and it is a low-tech and easy way to edit OpenStreetMap. GPS and prior knowledge of GIS is not required for using Field Paper to map.

References:

- OpenStreetMap Wiki, Field Papers-http://wiki.openstreetmap.org/wiki/Field_Papers

- Field Papers, About Field Papers-http:/ / fieldpapers.org/about

(7) OSMTracker

Description: OSMTracker is a mobile application used offline to track and save both positional (latitude/longitude) and non-positional (names, height of the structure, date of construction, etc.) data of Points of Interest (POIs). OSMTracker data is exported in GPX format with waypoints, making it suitable for import into the JOSM map editor. OSMTracker can be used in parallel with Field Paper in field survey of communities. The application has two versions for Android and Windows Mobile. HOTOSM team recently developed a new application Geo-Data-Collect, based on OSM-Tracker and ODK-Collect. This new app have both GPS tracker capabilities and form collection capabilities.

References:

- OpenStreetMap Wiki, OSMTracker-http://wiki.openstreetmap.org/wiki/OSMtracker

- HOTOSM, OSMTracker-http://learnosm.org/en/mobile-mapping/osmtracker/

- HOTOSM, Geo-Data-Collect-https://play.google.com/store/apps/details?id=hosm.odk.collect. android\&hl=en

(8) JOSM

Description: JOSM, or Java OpenStreetMap Editor, is a powerful and stable desktop application that allows users to edit OpenStreetMap data while offline. JOSM supports loading GPX tracks from OSMTracker, background imagery and OSM data from local sources, as well as from online sources and allows to edit the OSM data (nodes, ways, and relations), and their metadata tags. JOSM is a feature-rich editor with a rather complex interface, thus it has a relatively steep learning curve.

Reference

- JOSM-https://josm.openstreetmap.de/

- OSM, Java OpenStreetMap Editor-http://wiki.openstreetmap.org/wiki/JOSM 
- HOTOSM, JOSM—Detailed Editing—http://learnosm.org/en/josm/

\section{(9) QGIS}

Description: A geographical information system (GIS) is a system designed to capture, store, manipulate, analyze, manage, and present all types of spatial or geographical data. QGIS is a free and open source GIS that allows geospatial data viewing, editing and analysis. QGIS is a volunteer-driven project and is preferred over other GIS software because of its user-friendly interface, fast development and wide functionality. QGIS runs on multiple operating systems including Mac OS X, Linux, UNIX, and Microsoft Windows. QGIS has a small file size compared to commercial GIS's and requires less RAM and processing power; hence it can be used on older hardware or running simultaneously with other applications where CPU power may be limited. QGIS is maintained by volunteer developers who regularly release updates and bug fixes. As of 2012, developers have translated QGIS into 48 languages and the application is used internationally in academic and professional environments.

References:

- QGIS, QGIS Documentation—https://qgis.org/en/docs/index.html

- OSM, Customized map making using QGIS—http://wiki.openstreetmap.org/wiki/QGIS

\section{References}

1. World Economic Forum. The Global Risks Report 2017; World Economic Forum: Geneva, Switzerland, 2017.

2. Forzieri, G.; Cescatti, A.; e Silva, F.B.; Feyen, L. Increasing risk over time of weather-related hazards to the european population: A data-driven prognostic study. Lancet Planet. Health 2017, 1, e200-e208. [CrossRef]

3. World Bank. World Development Report 2014, Risk and Opportunity: Managing Risk for Development; The World Bank: Washington, DC, USA, 2013.

4. Guha-Sapir, D.; Below, R.; Hoyois, P. EM-DAT: The CRED/OFDA International Disaster Database-wwww.Emdat. $\mathrm{Be}$; Université Catholique de Louvain; Université Catholique de Louvain: Brussels, Belgium, 2016.

5. Winsemius, H.; Ward, P. Aqueduct Global Flood Risk Country Rankings; World Resources Institute: Washington, DC, USA, 2015.

6. Challies, E.; Newig, J.; Thaler, T.; Kochskämper, E.; Levin-Keitel, M. Participatory and collaborative governance for sustainable flood risk management: An emerging research agenda. Environ. Sci. Policy 2016, 55, 275-280. [CrossRef]

7. Keating, A.; Campbell, K.; Mechler, R.; Magnuszewski, P.; Mochizuki, J.; Liu, W.; Szoenyi, M.; McQuistan, C. Disaster resilience: What it is and how it can engender a meaningful change in development policy. Dev. Policy Rev. 2017, 35, 65-91. [CrossRef]

8. UNISDR. Sendai Framework for Disaster Risk Reduction. Available online: http://www.unisdr.org/we/ coordinate/sendai-framework (accessed on 18 December 2016).

9. Gibson, T.; Pelling, M.; Ghosh, A.; Matyas, D.; Siddiqi, A.; Solecki, W.; Johnson, L.; Kenney, C.; Johnston, D.; Du Plessis, R. Pathways for transformation: Disaster risk management to enhance resilience to extreme events. J. Extreme Events 2016, 3, 1671002. [CrossRef]

10. Pelling, M. Transformation: A renewed window on development responsibility for risk management. J. Extreme Events 2014, 1, 1402003. [CrossRef]

11. Manyena, S.B.; O’Brien, G.; O'Keefe, P.; Rose, J. Disaster resilience: A bounce back or bounce forward ability? Local Environ. 2011, 16, 417-424.

12. Keating, A.; Campbell, K.; Szoenyi, M.; McQuistan, C.; Nash, D.; Burer, M. Development and testing of a community flood resilience measurement tool. Nat. Hazards Earth Syst. Sci. Discuss. 2016, 2016, 1-39. [CrossRef]

13. Hirabayashi, Y.; Mahendran, R.; Koirala, S.; Konoshima, L.; Yamazaki, D.; Watanabe, S.; Kim, H.; Kanae, S. Global flood risk under climate change. Nature Clim. Chang. 2013, 3, 816-821. [CrossRef]

14. Philip, J.W.; Brenden, J.; Frederiek Sperna, W.; Arno, B.; van Rens, B.; Marc, F.P.B.; Willem, L.; Hessel, C.W. Assessing flood risk at the global scale: Model setup, results, and sensitivity. Environ. Res. Lett. 2013, 8, 044019. [CrossRef] 
15. Van Der Knijff, J.M.; Younis, J.; De Roo, A.P.J. Lisflood: A GIS-based distributed model for river basin scale water balance and flood simulation. Int. J. Geogr. Inf. Sci. 2010, 24, 189-212. [CrossRef]

16. Kugler, Z.; De Groeve, T.; Thierry, B. Towards a Near-Real Time Global Flood Detection System; European Commission Directorate-General Joint Research Centre: Brussels, Belgium, 2006.

17. Mueller, N.; Lewis, A.; Roberts, D.; Ring, S.; Melrose, R.; Sixsmith, J.; Lymburner, L.; McIntyre, A.; Tan, P.; Curnow, S.; et al. Water observations from space: Mapping surface water from 25 years of Landsat imagery across Australia. Remote Sens. Environ. 2016, 174, 341-352. [CrossRef]

18. Pekel, J.-F.; Cottam, A.; Gorelick, N.; Belward, A.S. High-resolution mapping of global surface water and its long-term changes. Nature 2016, 540, 418-422. [CrossRef] [PubMed]

19. Alfieri, L.; Burek, P.; Dutra, E.; Krzeminski, B.; Muraro, D.; Thielen, J.; Pappenberger, F. Glofas-global ensemble streamflow forecasting and flood early warning. Hydrol. Earth Syst. Sci. 2013, 17, 1161-1175. [CrossRef]

20. Cutter, S.; Osman-Elasha, B.; Campbell, J.; Cheong, S.-M.; McCormick, S.; Pulwarty, R.; Supratid, S.; Ziervogel, G. Managing the Risks from Climate Extremes at the Local Level. In Managing the Risks of Extreme Events and Disasters to Advance Climate Change Adaptation: Special Report of Working Groups I and II of the Intergovernmental Panel on Climate Change; Field, C.B., Barros, V., Stocker, T.F., Qin, D., Dokken, D.J., Ebi, K.L., Mastrandrea, M.D., Mach, K.J., Plattner, G.K., Allen, S.K., et al., Eds.; Cambridge University Press: Cambridge, UK, 2012; pp. 291-338.

21. Ward, P.J.; Jongman, B.; Salamon, P.; Simpson, A.; Bates, P.; De Groeve, T.; Muis, S.; de Perez, E.C.; Rudari, R.; Trigg, M.A.; et al. Usefulness and limitations of global flood risk models. Nature Clim. Chang. 2015, 5, 712-715. [CrossRef]

22. Buytaert, W.; Dewulf, A.; De Bièvre, B.; Clark, J.; Hannah, D.M. Citizen science for water resources management: Toward polycentric monitoring and governance? J. Water Resour. Plan. Manag. 2016, 142, 01816002. [CrossRef]

23. Pelling, M. Learning from others: The scope and challenges for participatory disaster risk assessment. Disasters 2007, 31, 373-385. [CrossRef] [PubMed]

24. IFRC. Vulnerability and Capacity Assessment Tool Box; International Federation of Red Cross and Red Crescent: Geneva, Switzerland, 1996.

25. IFRC. VCA Toolbox with Reference Sheets; International Federation of Red Cross and Red Crescent: Geneva, Switzerland, 2007.

26. Chambers, R. The origins and practice of participatory rural appraisal. World Develop. 1994, 22, $953-969$. [CrossRef]

27. Gaillard, J.-C.; Maceda, E.A. Participatory three-dimensional mapping for disaster risk reduction. Commun. Based Adapt. Clim. Chang. 2009, 60, 109-118.

28. Kienberger, S. Participatory mapping of flood hazard risk in Munamicua, District of Búzi, Mozambique. J. Maps 2014, 10, 269-275. [CrossRef]

29. IFRC. Vulnerability and Capacity Assessment (VCA) and Other Assessment Tools. Available online: http:/ / www.rcrc-resilience-southeastasia.org/disaster-risk-reduction/community-based-disasterrisk-reduction/vulnerability-and-capacity-assessment-vca-and-other-assessment-tools/ (accessed on 9 December 2016).

30. Turnbull, M.; Turvill, E. Participatory Capacity and Vulnerability Analysis: A Practitioner's Guide; Oxfam GB: Oxford, UK, 2012.

31. Dazé, A.; Ambrose, K.; Ehrhart, C. Climate Vulnerability and Capacity Analysis Handbook; Care International: Atlanta, GA, USA, 2009.

32. Corbett, J. Good Practices in Participatory Mapping: A Review Prepared for the International Fund for Agricultural Development (IFAD); IFAD: Rome, Italy, 2009.

33. Haworth, B.; Whittaker, J.; Bruce, E. Assessing the application and value of participatory mapping for community bushfire preparation. Appl. Geogr. 2016, 76, 115-127. [CrossRef]

34. Usón, T.J.; Klonner, C.; Höfle, B. Using participatory geographic approaches for urban flood risk in Santiago de Chile: Insights from a governance analysis. Environ. Sci. Policy 2016, 66, 62-72. [CrossRef]

35. Goodchild, M.F. Citizens as sensors: The world of volunteered geography. GeoJournal 2007, 69, $211-221$. [CrossRef] 
36. Sui, D.; Goodchild, M. The convergence of GIS and social media: Challenges for GIScience. Int. J. Geogr. Inf. Sci. 2011, 25, 1737-1748. [CrossRef]

37. See, L.; Mooney, P.; Foody, G.; Bastin, L.; Comber, A.; Estima, J.; Fritz, S.; Kerle, N.; Jiang, B.; Laakso, M.; et al. Crowdsourcing, citizen science or volunteered geographic information? The current state of crowdsourced geographic information. ISPRS Int. J. Geo-Inf. 2016, 5, 55. [CrossRef]

38. Harvey, F. To volunteer or to contribute locational information? In Crowdsourcing Geographic Knowledge: Volunteered Geographic Information (VGI) in Theory and Practice; Sui, D., Elwood, S., Goodchild, M., Eds.; Springer Netherlands: Dordrecht, The Netherlands, 2013; pp. 31-42.

39. Stefanidis, A.; Crooks, A.; Radzikowski, J. Harvesting ambient geospatial information from social media feeds. GeoJournal 2013, 78, 319-338. [CrossRef]

40. Haklay, M.; Weber, P. Openstreetmap: User-generated street maps. IEEE Pervasive Comput. 2008, 7, 12-18. [CrossRef]

41. Mooney, P.; Corcoran, P. Has openstreetmap a role in digital earth applications? Int. J. Digit. Earth 2014, 7, 534-553. [CrossRef]

42. Neis, P.; Zielstra, D. Recent developments and future trends in volunteered geographic information research: The case of openstreetmap. Future Int. 2014, 6, 76-106. [CrossRef]

43. Liu, S.B.; Palen, L. The new cartographers: Crisis map mashups and the emergence of neogeographic practice. Cartogr. Geogr. Inf. Sci. 2010, 37, 69-90. [CrossRef]

44. Burns, R. Moments of closure in the knowledge politics of digital humanitarianism. Geoforum 2014, 53, 51-62. [CrossRef]

45. Burns, R. Rethinking big data in digital humanitarianism: Practices, epistemologies, and social relations. GeoJournal 2015, 80, 477-490. [CrossRef]

46. Dittus, M. Large-scale volunteer engagement in humanitarian mapping. In Proceedings of the 19th ACM Conference on Computer Supported Cooperative Work and Social Computing Companion, San Francisco, CA, USA, 27 February-2 March 2016; pp. 139-142.

47. Poiani, T.H.; Rocha, R.D.S.; Degrossi, L.C.; de Albuquerque, J.P. Potential of collaborative mapping for disaster relief: A case study of openstreetmap in the Nepal earthquake 2015. In Proceedings of the 2016 49th Hawaii International Conference on System Sciences (HICSS), Kauai, HI, USA, 5-8 June 2016; pp. 188-197.

48. Haworth, B.; Bruce, E. A review of volunteered geographic information for disaster management. Geogr. Compass 2015, 9, 237-250. [CrossRef]

49. McCallum, I.; Liu, W.; See, L.; Mechler, R.; Keating, A.; Hochrainer-Stigler, S.; Mochizuki, J.; Fritz, S.; Dugar, S.; Arestegui, M.; et al. Technologies to support community flood disaster risk reduction. Int. J. Disaster Risk Sci. 2016, 7, 198-204. [CrossRef]

50. Verplanke, J.; McCall, M.K.; Uberhuaga, C.; Rambaldi, G.; Haklay, M. A shared perspective for PGIS and VGI. Cartogr. J. 2016, 53, 308-317. [CrossRef]

51. Dilley, M.; Chen, R.S.; Deichmann, U.; Lerner-Lam, A.L.; Arnold, M.; Agwe, J.; Buys, P.; Kjevstad, O.; Lyon, B.; Yetman, G. Natural Disaster Hotspots: A Global Risk Analysis; World Bank: Washington, DC, USA, 2005.

52. Zurich Insurance Group. Risk Nexus: Urgent Case for Recovery: What We Can Learn from the August 2014 Karnali River Floods in Nepal; Zurich Insurance Group Ltd.: Zurich, Switzerland, 2015.

53. NPC Nepal; UNDP. Nepal Human Development Report 2014: Beyond Geography, Unlocking Human Potential; NPC Nepal: Kathmandu, Nepal, 2014.

54. Government of Nepal Rajapur Municipality. Brief Introduction of the Rajapur Municipality. Available online: http:/ / www.rajapurmun.gov.np/ne/node/3 (accessed on 9 December 2016).

55. OpenStreetMap. Nepal Remote Mapping Guide. Available online: http://wiki.openstreetmap.org/wiki/ Nepal_remote_mapping_guide (accessed on 15 December 2016).

56. Liu, W. From the Himalayas to the Andes: Crowdsourced disaster risk mapping. In Nexus-The Research Blog of IIASA; IIASA: Laxenburg, Austria, 2017.

57. Practical Action Nepal. Community Based Disaster Risk Management Plan-Chakkhapur Village, Rajapur Municipality, Bardia; Practical Action Nepal: Warwickshire, UK, 2015.

58. Corbett, J.; Cochrane, L.; Gill, M. Powering up: Revisiting participatory GIS and empowerment. Cartogr. J. 2016, 53, 335-340. [CrossRef] 
59. Sui, D.; Goodchild, M.; Elwood, S. Volunteered geographic information, the exaflood, and the growing digital divide. In Crowdsourcing Geographic Knowledge: Volunteered Geographic Information (VGI) in Theory and Practice; Sui, D., Elwood, S., Goodchild, M., Eds.; Springer Netherlands: Dordrecht, The Netherlands, 2013; pp. 1-12.

60. WMO. Winners of the global competition for youth-led projects on floods and droughts. MeteoWorld 2017, $2,657$.

61. Van Dijk, J.; Hacker, K. The digital divide as a complex and dynamic phenomenon. Inf. Soc. 2003, 19, 315-326. [CrossRef]

62. Nepal Telecommunications Authority. Nepal Telecommunications Authority MIS Report-Bhadra, 2074 (17 August 2017-16 September 2017); Nepal Telecommunications Authority: Kathmandu, Nepal.

63. Neupane, N. Nepal Added Over 250 Internet Users Per Hour. Available online: http: / / kathmandupost.ekantipur.com/news/2018-01-20/nepal-added-over-250-internet-users-per-hour.html (accessed on 21 January 2018).

(C) 2018 by the authors. Licensee MDPI, Basel, Switzerland. This article is an open access article distributed under the terms and conditions of the Creative Commons Attribution (CC BY) license (http://creativecommons.org/licenses/by/4.0/). 